\title{
First in situ measurement of electric field fluctuations during strong spread $F$ in the Indian zone
}

\author{
H. S. S. Sinha, S. Raizada \\ Physical Research Laboratory, Navrangpura, Ahmedabad - 380 009, India \\ Received: 22 October 1999 / Revised: 31 January 2000 / Accepted: 4 February 2000
}

\begin{abstract}
An RH-560 rocket flight was conducted from Sriharikota rocket range (SHAR) $\left(14^{\circ} \mathrm{N}, 80^{\circ} \mathrm{E}\right.$, dip $14^{\circ} \mathrm{N}$ ) along with other experiments, as a part of equatorial spread $F$ (ESF) campaign, to study the nature of irregularities in electric field and electron density. The rocket was launched at 2130 local time (LT) and it attained an apogee of $348 \mathrm{~km}$. Results of vertical and horizontal electric field fluctuations are presented here. Scale sizes of electric field fluctuations were measured in the vertical direction only. Strong ESF irregularities were observed in three regions, viz., 160 $190 \mathrm{~km}, 210-257 \mathrm{~km}$ and $290-330 \mathrm{~km}$. Some of the valley region vertical electric field irregularities (at $165 \mathrm{~km}$ and $168 \mathrm{~km}$ ), in the intermediate-scale size range, observed during this flight, show spectral peak at kilometer scales and can be interpreted in terms of the image striation theory suggested by Vickrey et al. The irregularities at $176 \mathrm{~km}$ do not exhibit any peak at kilometer scales and appear to be of a new type. Scale sizes of vertical electric field fluctuations showed a decrease with increasing altitude. The most prominent scales were of the order of a few kilometers around $170 \mathrm{~km}$ and a few hundred meters around $310 \mathrm{~km}$. Spectra of intermediate-scale vertical electric field fluctuations below the base of the $F$ region $(210-257 \mathrm{~km})$ showed a tendency to become slightly flatter (spectral index $n=-2.1 \pm 0.7$ ) as compared to the valley region $(n=-3.6 \pm 0.8)$ and the region below the $F$ peak $(n=-2.8 \pm 0.5)$. Correlation analysis of the electron density and vertical electric field fluctuations suggests the presence of a sheared flow of current in $160-330 \mathrm{~km}$ region.
\end{abstract}

Keywords: Ionosphere (Electric fields and currents; ionospheric irregularities); Radio science (ionospheric physics)

Correspondence to: $\mathrm{H}$. S. S. Sinha

e-mail: hsinha@prl.ernet.in

\section{Introduction}

It is very well known that the ionospheric electric field plays an important role in low-latitude electrodynamics. In the equatorial $\mathrm{E}$ region the zonal east-west field drives the equatorial electrojet (Richmond 1973; Forbes and Lindzen, 1977) and associated plasma instabilities which manifest as electron density and electric field fluctuations (Prakash et al., 1972; Fejer and Kelley, 1980; Pfaff et al., 1982, 1988a, b; Kudeki et al., 1998). In the F region, the zonal field results in the plasma transport across the magnetic field lines due to $\mathbf{E} \times \mathbf{B}$ drift at the equator. This daytime upward drift and subsequent diffusion along the field lines result in ionization transport towards higher latitudes, causing an Appleton or equatorial anomaly (Moffett, 1979; Anderson, 1981; Sastri, 1990).

Electric fields in the ionosphere arise when the ions and electrons respond differently to the forces acting on them. These forces may be related to the plasma pressure gradients, magnetic and gravitational fields and atmospheric winds. Earle and Kelley (1987) performed spectral analysis of a number of incoherent scatter data sets obtained from various locations to try to understand the sources of electric field fluctuations with periods in the range of $1-10 \mathrm{~h}$. It was shown that for this range of periods, the zonal electric field at Jicamarca has a transition from atmospheric to magnetospheric sources at $K_{p}$ level $\sim 3$. Balan et al. (1993) presented power spectra of the fluctuating component of the east-west electric field at the magnetic equator. They found that the spectra displayed very little day-to-day variability and had no appreciable change with magnetic activity. From the spectral characteristics of electric field they suggested that the medium-scale gravity waves could be a source for the observed fluctuations of zonal fields in the post-sunset F-region. Vishwanathan et al. (1993) found good a correlation between $\mathrm{E}$ and F-region electric field perturbations and suggested that the electric fields in the E-regions at low and equatorial 
latitudes are coherent for the temporal scales of the order of few tens of minutes. They attributed the observed fluctuations in E and F-region electric fields to medium-scale gravity waves.

Electric field measurements in the equatorial regions have been carried out using both ground-based and in situ techniques. The ground-based technique which has yielded very significant data on the $\mathrm{F}$ region electric fields is the $50 \mathrm{MHz}$ incoherent scatter radar at Jicamarca. In this technique, electric fields are derived from the drifts, which are measured directly by using two radar beams perpendicular to the geomagnetic field at F region altitudes (Woodman, 1970; Balsley, 1975; Woodman et al., 1977; Fejer et al., 1979, 1991; Kudeki et al., 1999). The other important ground-based techniques include, spaced receivers (Chandra et al., 1970; Rastogi et al., 1972), interferometry (Kudeki et al., 1981), and vapor cloud experiments (Rees et al., 1976; Raghavarao et al., 1984). In situ measurements have provided a wealth of information about the electric fields and the dynamics of intense plasma depletions. In situ techniques include both the satellite (Kelley and Mozer, 1972; Aggson et al., 1992, 1995; Maynard et al., 1995; Laakso et al., 1994, 1997) and rocket (Kelley et al., 1982; Prakash et al., 1983; Prakash and Pal, 1985; Pal et al., 1983; LaBelle et al., 1986, 1997; Raghavarao et al., 1987; Jahn et al., 1997) experiments.

First simultaneous measurements of electron density $\left(\mathrm{n}_{\mathrm{e}}\right)$ and electric field (EF) fluctuations, in the Indian zone, were made from Sriharikota rocket range (SHAR) $\left(14^{\circ} \mathrm{N}, 80^{\circ} \mathrm{E}\right.$, dip lat. $\left.5.5^{\circ} \mathrm{N}\right)$ during a fully developed spread $\mathrm{F}$ epoch. Results of in situ electron density measurements and ground based complementary experiments have already been reported (Chandra et al., 1997; Sinha et al., 1999; Raizada and Sinha, 1999). This work presents the results of in situ electric field measurements.

\section{Technique of electric field measurement}

Measurements of electric field fluctuations were made using the Langmuir double probe technique, wherein the potential difference between two conducting spheres, separated by a distance $d$, is measured. By mounting the conductor pairs in suitable directions, the electric field fluctuations in different directions can be measured. This method provides measurement of electric field fluctuations in the rocket frame of reference. These measurements can, in principle, be transformed into the Earth frame of reference as shown by Fredricks and Coroniti (1976) and Temerin (1979). This transformation is governed by the following equations:

$f_{R}=\left(V_{R} \cos \alpha-V_{P}\right) / \lambda_{E}$

$\lambda_{E}=\left\{\left(V_{R} \cos \alpha-V_{P}\right) \lambda_{R}\right\} / V_{R}=\left(V_{R} \cos \alpha-V_{P}\right) \tau_{R}$

where, $f_{R}$ is the frequency of electric field fluctuations in the rocket frame of reference, $V_{R}$ is the rocket velocity, $V_{P}$ is the phase velocity of plasma waves, $\lambda_{E}$ and $\lambda_{R}$ are the scale sizes of fluctuations in Earth and rocket frames of references, respectively, $\alpha$ is the angle between the rocket velocity vector and the wave number, $k_{E}$, in the Earth frame of reference $\left(k_{E}=2 \pi / \lambda_{E}\right)$ and $\tau_{R}$ is the wave period in rocket frame of reference.

This transformation from rocket to Earth frame of reference, becomes extremely complicated in the F-region due to the fact that the phase velocity of plasma waves is not very much smaller than the velocity of rocket and also because it is not known accurately. Hence the measurements reported here are only in rocket frame of reference.

For a double probe system, the potential developed between two sensors has been discussed in detail by Fahleson (1967) and Fahleson et al. (1970) and is given by:

$\Phi=\left(\mathbf{E}+\mathbf{V}_{R} \times \mathbf{B}\right) \cdot \mathbf{d}+V_{C}$

where, $\Phi$ is the potential difference between two sensors, $\mathbf{E}$ is the ambient electric field in earth's frame of reference, $\mathbf{V}_{R}$ is the rocket velocity vector, $\mathbf{B}$ is the magnetic field of the earth, $\mathbf{d}$ is the vector distance between two sensors and $V_{C}$ is the contact potential difference between two sensors.

The term $\mathbf{V}_{R} \times \mathbf{B}$ is known as the induced electric field and its nature, for sensor pairs along and across the spin axis of the rocket, is quite different. For E and Fregions, the magnitude of this induced field is in general larger that the field one tries to measure. This is, therefore, an unwanted field and must be removed very carefully. The procedure for its removal will be discussed in Sect. 4.

Another precaution to be taken is to ensure that rocket body is maintained at the floating potential. At the floating potential there is unobstructed flow of electrons and ions. If the flow of either electrons or ions is impeded due to the presence of some other body, the potential of both the sensors will be disturbed. The electrons, which move typically with a velocity of the order of $100 \mathrm{~km} \mathrm{~s}^{-1}$, which is much larger than the typical rocket velocity of $1-2 \mathrm{~km} \mathrm{~s}^{-1}$, are constrained to move along the geomagnetic field lines. This implies that no sensor or boom should come into the path of northsouth line passing through any of the electric field sensors. If any of the electric field sensors fall in the mechanical wake, the potential of that particular sensor will be disturbed leading to erroneous measurement of electric field. The ions, on the other hand, move with a typical velocity of a few $\mathrm{km} \mathrm{s}^{-1}$. Thus, with the supersonic motion of the rocket, ions will be swept by the moving rocket along its velocity vector. Hence none of the electric field sensors should have any obstruction along the velocity vector of the rocket. Lastly, the effect of contact potential difference between two sensors must be kept at minimum by applying proper conducting coating on all sensors.

\section{Flight details}

An RH 560 rocket, carrying two pairs of electric field double probes and a Langmuir probe, was launched 
from SHAR $\left(14^{\circ} \mathrm{N}, 80^{\circ} \mathrm{E}\right.$, dip $\left.14^{\circ} \mathrm{N}\right)$, India at $2130 \mathrm{~h}$ on 4 , October, 1988. The rocket, which was launched due east of the SHAR with an elevation of $81.25^{\circ}$ and azimuth of approximately $82^{\circ}$, attained an apogee of $348 \mathrm{~km}$. The arrangement of sensors on this flight is shown in Fig. 1. Two pairs of the double probes were used to measure the fluctuations of the electric field along and perpendicular to the spin axis of the rocket. The electric field probes A, C and D had a diameter of $50 \mathrm{~mm}$ and the probe $\mathrm{B}$ had a diameter of $60 \mathrm{~mm}$. The higher diameter of probe $\mathrm{B}$ was to increase its effective area of cross section, which is reduced due to the passage of the central boom through this sensor. All the electric field sensors were made of aluminum and were gold plated to minimize the effect of contact potential difference. All the three booms supporting the sensors were of bi-stem type and were stored in a folded condition before the launch. A boom deployment mechanism was used to deploy all three booms supporting the electric field and Langmuir probe sensors. The separation between sensors A and B and C and D was $1000 \mathrm{~mm}$ and $2400 \mathrm{~mm}$, respectively. The double probe system flown on RH-560 rocket on October 4, 1988, was essentially similar to that discussed by $\mathrm{Pal}$ et al. (1983).

Band pass filters were used to study the small-scale fluctuations in the electric field. Data were separated into two channels (a) $\mathrm{DC}-100 \mathrm{~Hz}$ for studying large-scale structures and (b) $50-500 \mathrm{~Hz}$, for studying medium-scale structures. The pass band in the latter frequency range corresponded to irregularities with scale-sizes in the range of $30 \mathrm{~m}$ to $3 \mathrm{~m}$ for a rocket moving with a velocity of about $1.5 \mathrm{~km} \mathrm{~s}^{-1}$. An extra gain of about 30 was given to the signals during the filtering process. A constant current of about $90 \mathrm{nA}$ was fed to each of the electric field sensors to reduce the

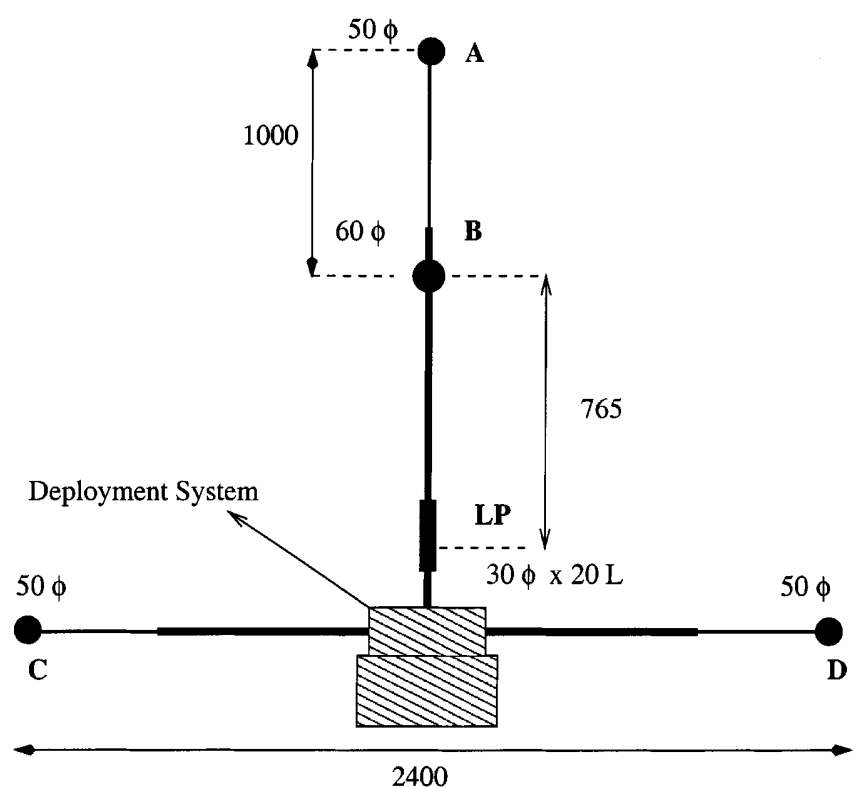

Fig. 1. Geometry of electric field and Langmuir probe sensors flown on the RH-560 rocket from SHAR sheath resistance, which in turn results in increased frequency response. To reduce the contact potential asymmetry on the sensor surface, a uniform coating of gold was applied to each sensor.

As mentioned earlier, the $\mathbf{V} \times \mathbf{B}$ induced field arises due to the motion of the double probe system across the geomagnetic field B. Figure 2 shows a schematic of the location of various sensors vis-à-vis the directions of the magnetic field, spin axis, rocket velocity vector, etc. An estimation of the magnitude of the $\mathbf{V} \times \mathbf{B}$ term has been made along the spin axis of the rocket and also across it during the course of the rocket flight. If $\varphi$ is the dip angle of the location of the rocket at any instant and $\varphi^{\prime}$ is the angle which the velocity vector makes with the geomagnetic north i.e., azimuth of the rocket, then the induced fields along the spin axis and perpendicular to it are given by:

$$
\begin{gathered}
\Phi_{\|}=\mathbf{B} \sqrt{\mathbf{V}_{V}^{2}+\mathbf{V}_{H}^{2}} \sin \left(\varphi+\varphi^{\prime}\right) \cos \left[\tan ^{-1}\left(\frac{\mathbf{V}_{V}}{\mathbf{V}_{H}}\right) \pm \theta\right] \\
\Phi_{\perp}=\mathbf{B} \sqrt{\mathbf{V}_{V}^{2}+\mathbf{V}_{H}^{2}} \sin \left(\varphi+\varphi^{\prime}\right) \sin \left[\tan ^{-1}\left(\frac{\mathbf{V}_{V}}{\mathbf{V}_{H}}\right) \pm \theta\right]
\end{gathered}
$$

where $\theta$ is the angle between the rocket spin axis and the vertical, $\mathbf{V}_{V}$ and $\mathbf{V}_{H}$ are the vertical and horizontal components of the rocket velocity respectively, and $B$ is the Earth's magnetic field. Here the plus sign is applicable during ascent and the minus sign during

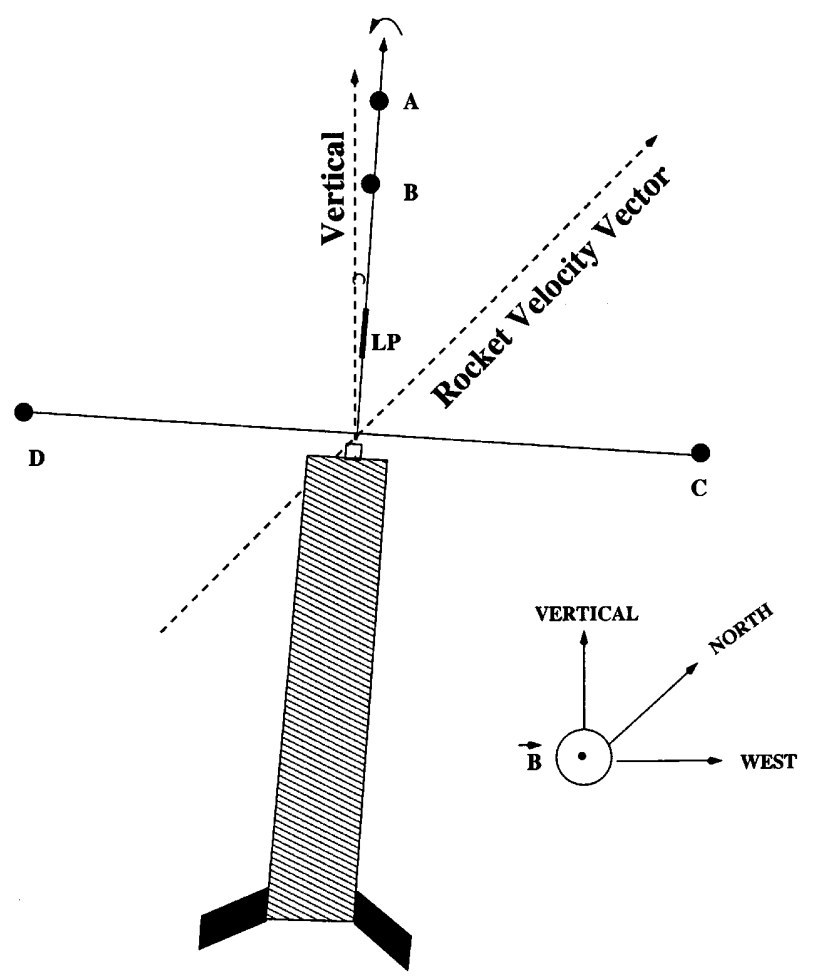

Fig. 2. Schematic of the location of electric field and the Langmuir probe sensors vis-à-vis the directions of the magnetic field, the spin axis and the rocket velocity vector 


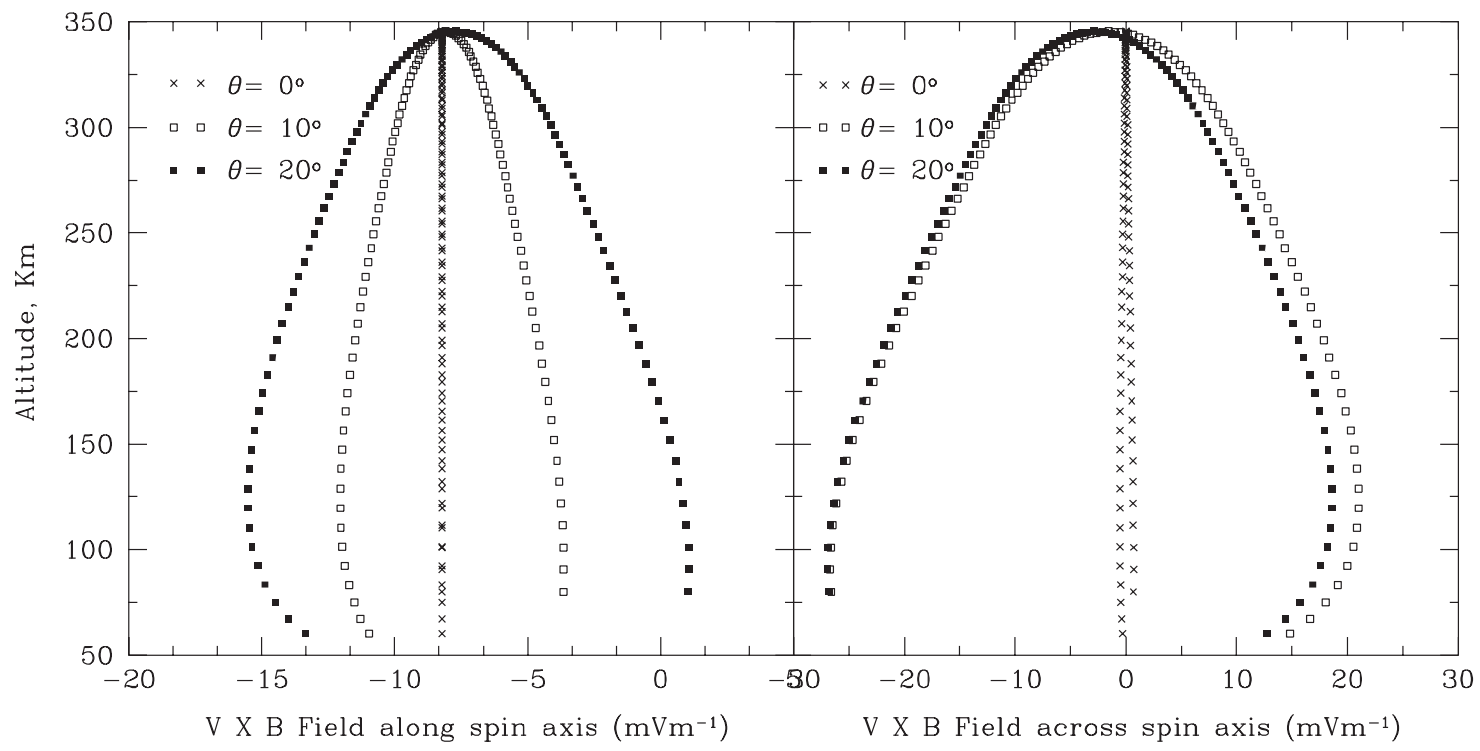

Fig. 3. Electric field induced due to the $\mathbf{V} \times \mathbf{B}$ effect along the spin axis (left panel) and across the spin axis (right panel) for three values of $\theta$, which is the angle between the spin axis and the vertical

descent. Figure 3 shows the $\mathbf{V} \times \mathbf{B}$ component induced along and perpendicular to the spin axis for different values of the rocket orientation angle $\theta$. It can be seen from these figures that (a) as $\theta$ increases, the induced field during the ascent and the descent also increases and (b) the difference between the $\mathbf{V} \times \mathbf{B}$ component during the upleg and the downleg motion of the rocket is more for the component of the induced field across the rocket spin axis compared to that induced along it.

\section{Vertical electric field $\left(E_{V}^{\prime}\right)$}

The potential difference between sensors A and B has been used to estimate the electric field along the spin axis of the rocket. The elevation of the rocket was $81.25^{\circ}$, its precession angle was within $\pm 7.5^{\circ}$, precession period was $20 \mathrm{~s}$ and the spin axis was fairly stable in space with a spin rate of $3.5 \mathrm{~Hz}$. Thus the electric field along the spin axis $\left(E_{V}^{\prime}\right)$ represents electric field in a direction which is slightly off the vertical. As the precession period was $20 \mathrm{~s}$, vertical electric field structures up to a few $\mathrm{km}$ scale sizes could be studied practically without any $\mathbf{V} \times \mathbf{B}$ correction. The contact potential effects can not be corrected for the vertical electric field, but in view of the fact that contact potential difference between sensors $\mathrm{A}$ and $\mathrm{B}$ is a slowly varying function of time, it does not create any serious problem for studying the fluctuations in electric field. The $\mathbf{V} \times \mathbf{B}$ effect was removed by taking a running average of $10 \mathrm{~s}$ of data and then subtracting the running average from the original data. Vertical electric field fluctuations over larger scale sizes $(\lambda>400 \mathrm{~m})$ were studied by employing a low pass filter with a cut off frequency of $3 \mathrm{~Hz}$. The time series of vertical electric field fluctuations obtained from the two channels, viz., DC-100 Hz and $50-500 \mathrm{~Hz}$ was subjected to the fast Fourier transform (FFT) technique to determine the amplitude of dominant frequencies. The frequencies were converted in to vertical scale sizes using the relation $\lambda_{v}=\mathbf{V}_{R} / f$, where $\lambda_{v}$ is the vertical scale size corresponding to the frequency $f$ and $\mathbf{V}_{R}$ is the vertical component of the rocket velocity.

The top panel of Fig. 4 shows the variation of $\delta \mathrm{E}_{V}^{\prime}$, from $130 \mathrm{~km}$ to the apogee of the rocket. Strongest electric field perturbations of $11.5 \mathrm{mV} \mathrm{m}^{-1}$ and $13.5 \mathrm{mV} \mathrm{m}^{-1}$ were observed at $135 \mathrm{~km}$ and $175 \mathrm{~km}$, respectively. Although the electric field fluctuations were present right up to the apogee of the rocket, significant fluctuations were found in three distinct altitude regions of $160-190 \mathrm{~km}, 210-257 \mathrm{~km}$ and $290-330 \mathrm{~km}$, in addition to the lowermost structure around $135 \mathrm{~km}$. In the first region, perturbations from 5 to $13.5 \mathrm{mV} \mathrm{m}^{-1}$ having a vertical scale size range of 1 to $4 \mathrm{~km}$ were quite prominent. The electric field in these structures increased by a factor of up to 5 in a few kilometers of vertical extent. Smaller scale structures of a few hundred meters were also seen superposed on these. In the altitude region of 210 to $257 \mathrm{~km}$, the amplitude of perturbations ranged between 0.5 to $4 \mathrm{mV} \mathrm{m}^{-1}$. The vertical scale size of these structures ranged between 0.25 to $3 \mathrm{~km}$. In the topmost region ( $290 \mathrm{~km}$ to the apogee), both the amplitude and vertical scale size of the perturbations decreased and, in general, their maximum values were $3 \mathrm{mV} \mathrm{m}^{-1}$ and $1 \mathrm{~km}$, respectively.

\section{Horizontal electric field $\left(E_{H}^{\prime}\right)$}

The electric field component $E_{H}^{\prime}$ represents electric field in a direction perpendicular to $E_{V}^{\prime}$, and hence would represent the horizontal electric field component fairly well. $E_{H}^{\prime}$ is derived from the potential difference between sensors $\mathrm{C}$ and $\mathrm{D}$. The raw data of $E_{H}^{\prime}$ exhibits a sinusoidal variation corresponding to the spin frequency of the rocket and a dc shift which may be due to the slowly changing contact potential difference between the 


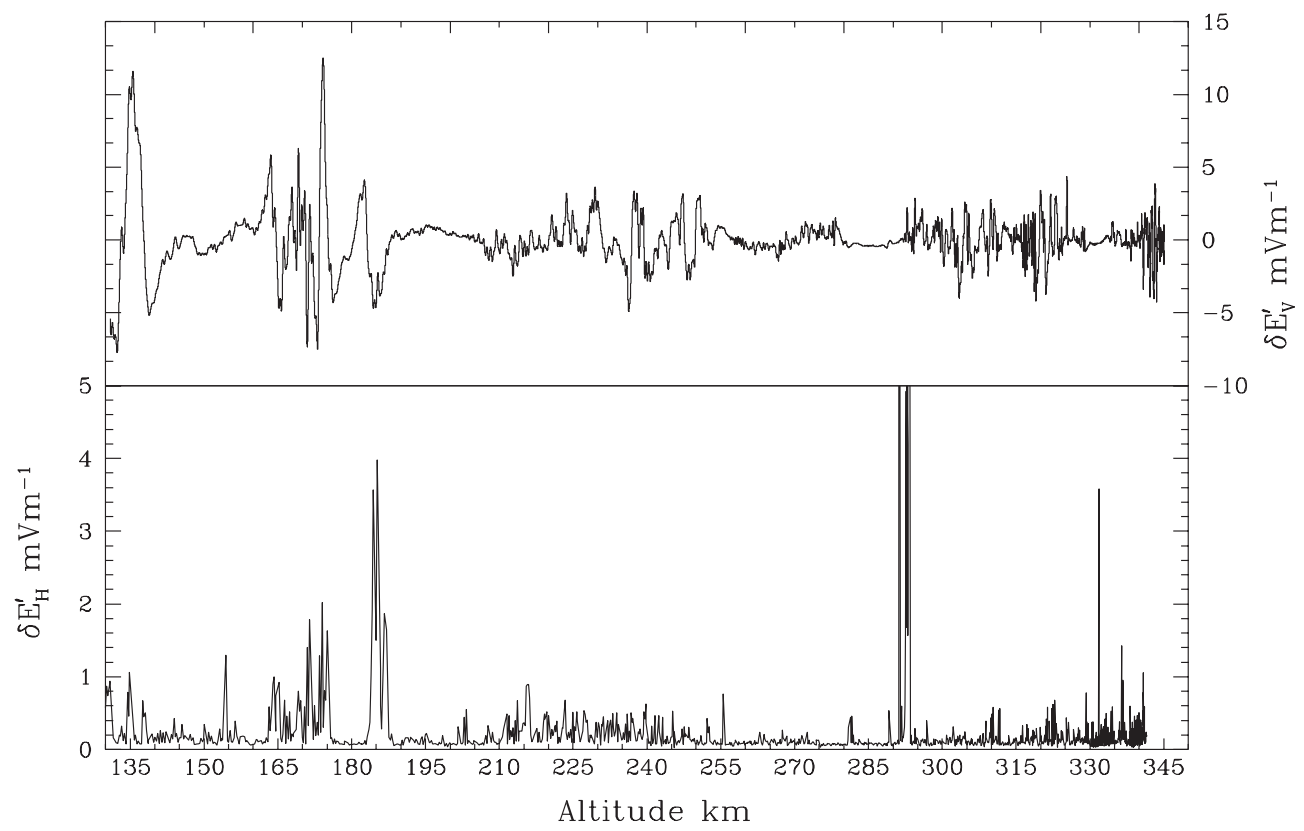

Fig. 4. Electric field fluctuations in the vertical (upper panel) and horizontal (lower panel) directions observed over SHAR sensors $\mathrm{C}$ and $\mathrm{D}$. The dc shift was eliminated by taking average of $2 \mathrm{~s}$ of data and subtracting it from the corresponding raw data set. When the angle between the distance vector, $\mathbf{d}$ (representing the separation between the side sensors) and $\mathbf{B}$ (representing the geomagnetic field line) becomes $0^{\circ}$, the potential of both sensors, $\mathrm{C}$ and $\mathrm{D}$ gets totally disturbed and can not be used to derive electric field values. The potential of sensors $\mathrm{C}$ and $\mathrm{D}$ is least disturbed when this angle is $90^{\circ}$. In view of this, only those values of potential difference were used which lie within $90^{\circ} \pm 15^{\circ}$ of this angle. Thus two sets of values of potential difference were obtained during each spin cycle. Root mean square values of both the sets, thus yield two values of $E_{H}^{\prime}$ in one spin cycle.

The lower panel of Fig. 4 shows the variation of $\delta E_{H}^{\prime}$, from $130 \mathrm{~km}$ to the apogee of the rocket. As seen in Fig. $4, \delta E_{H}^{\prime}$ also exhibits fluctuations in those regions where $\delta E_{V}^{\prime}$ fluctuations are significant but the amplitude of $\delta E_{H}^{\prime}$ fluctuations is, in general, not as large as that of $\delta E_{V}^{\prime}$. In $160-190 \mathrm{~km}$ region, where the strongest vertical electric field variations were observed, $\delta E_{H}^{\prime}$ also shows large amplitudes up to about $2 \mathrm{mV} \mathrm{m}^{-1}$. $\delta E_{H}^{\prime}$ exhibits a very large value of $4 \mathrm{mV} \mathrm{m}^{-1}$, with a half width of $3.6 \mathrm{~km}$, in $184-188 \mathrm{~km}$ region. It is interesting to note that $\delta E_{V}^{\prime}$ also shows very large fluctuations at this altitude. Beyond $188 \mathrm{~km}$, amplitude of horizontal electric field perturbations is smaller than $1 \mathrm{mV} \mathrm{m}^{-1}$, with the exception of two regions viz., around $292 \mathrm{~km}$ and $332-340 \mathrm{~km}$. In the $292 \mathrm{~km}$ region, the horizontal electric fields attain very high values, the highest value being $7.7 \mathrm{mV} \mathrm{m}^{-1}$. In the $332-340 \mathrm{~km}$ region, the enhancements of horizontal electric field are in the form of spikes with amplitudes of $4 \mathrm{mV} \mathrm{m}^{-1}$ and $1.5 \mathrm{mV} \mathrm{m}^{-1}$. These observations indicate that one can have pockets of very high horizontal electric fields. The typical scales of $\delta E_{H}^{\prime}$ are 1 to $4 \mathrm{~km}$ below about $220 \mathrm{~km}$ altitude and less than $0.5 \mathrm{~km}$ beyond $220 \mathrm{~km}$.

\section{Correlation between electric field and electron density fluctuations}

A correlation analysis between the $\delta n_{e}$ and $\delta E_{H}^{\prime}$ and between $\delta n_{e}$ and $\delta E_{V}^{\prime}$ fluctuations was made, using a vertical data length of $10 \mathrm{~km}$, for all the three important regions where the irregularities were seem prominently. Figure 5 shows three such data sets of $170-180 \mathrm{~km}$, $240-250 \mathrm{~km}$ and $290-300 \mathrm{~km}$ regions. In the 170 $180 \mathrm{~km}$ region, electron density fluctuations are very weak and in this case there is a very strong anticorrelation between $\delta n_{e}$ and $\delta E_{V}^{\prime}$ (correlation coefficient $=-0.83$ ). In $240-250 \mathrm{~km}$ region, on the other hand, $\delta n_{e}$ fluctuations are quite strong, but in this region $\delta n_{e}$ and $\delta E_{V}^{\prime}$ exhibit a very strong positive correlation characterized by a correlation coefficient of +0.9 . In the $290-300 \mathrm{~km}$ region, the amplitude of $\delta n_{e}$ fluctuations was again very small and a very strong anti-correlation (correlation coefficient $=-0.92$ ) was found between $\delta n_{e}$ and $\delta E_{V}^{\prime}$. The correlation between $\delta n_{e}$ and $\delta E_{H}^{\prime}$ was always extremely poor and did not show any dependence on the strength of $\delta n_{e}$ fluctuations.

\section{Spectra of electric field fluctuations}

Spectra of vertical electric field fluctuations $\left(\delta E_{V}^{\prime}\right)$ were obtained by making use of the data from two channels, viz., the DC $(0-100 \mathrm{~Hz})$ and MF $(50-500 \mathrm{~Hz})$ channels. As only two values of the horizontal electric field fluctuations were obtained during each spin cycle of the rocket, no attempt was made to construct the spectrum of $\delta E_{H}^{\prime}$. As mentioned earlier, significant electric field fluctuations (both in $\delta E_{V}^{\prime}$ and $\delta E_{H}^{\prime}$ ) were observed in three altitude regions, viz., $160-190 \mathrm{~km}, 210-257 \mathrm{~km}$ and $290-330 \mathrm{~km}$. Figure 6 shows the power spectra of the vertical electric field fluctuations $\left(\delta E_{V}^{\prime}\right)$ at three 

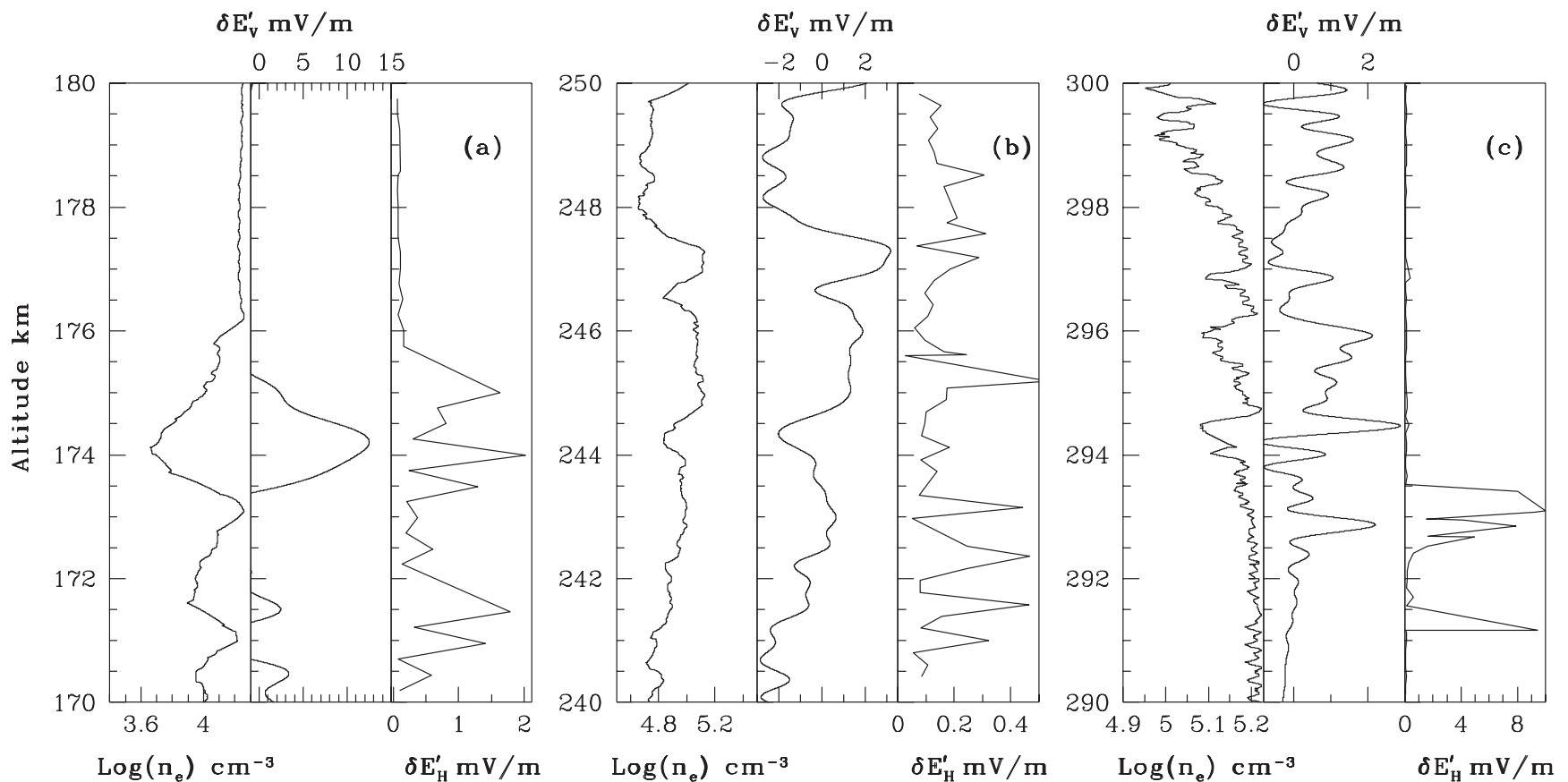

Fig. 5a-c. Electron density $\left(\delta n_{e}\right)$, vertical electric field $\left(\delta E_{V}^{\prime}\right)$ and horizontal electric field $\left(\delta E_{H}^{\prime}\right)$ fluctuations in a $170-180 \mathrm{~km}$, b $240-250 \mathrm{~km}$ and c $290-300 \mathrm{~km}$ regions

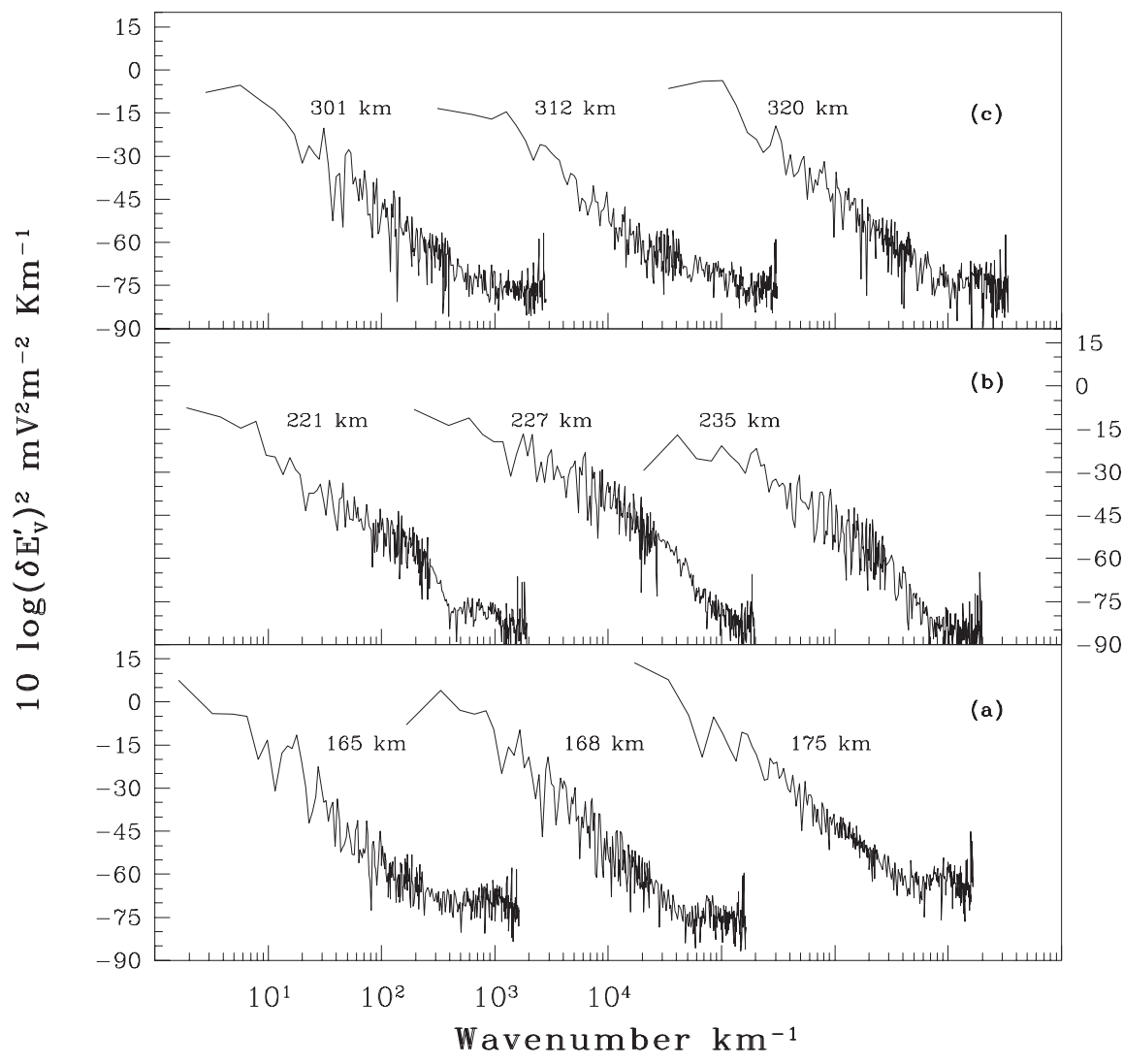

Fig. 6a-c. Spectra of vertical electric field fluctuations $\left(\delta E_{V}^{\prime}\right)$ at three representative altitudes a at $160-190 \mathrm{~km}$, b at $210-257 \mathrm{~km}$ and $\mathbf{c}$ at $290-330 \mathrm{~km}$ regions, which showed the presence of strong irregularities in electron density as well as electric fields altitudes in each of the three ranges. Except around $175 \mathrm{~km}$, all the spectra show a spectral peak, which lies in the range of $0.6 \mathrm{~km}$ to $2.0 \mathrm{~km}$. It is interesting to note that such peaks at kilometer scales were observed in the electron density spectra also, on the same flight and hence, these observations constitute the first simultaneous detection of spectral peaks in electric field and electron density at kilometer scales (Sinha et al., 1999; Raizada and Sinha 1999). As the spectrum becomes noisy at smaller scales, spectral index was computed at 
Table 1.

\begin{tabular}{lll}
\hline $\begin{array}{l}\text { Altitude } \\
(\mathrm{km})\end{array}$ & \multicolumn{1}{c}{ Spectral index } \\
\cline { 2 - 3 } & $\begin{array}{l}\text { Intermediate range } \\
(100 \mathrm{~m}-2 \mathrm{~km})\end{array}$ & $\begin{array}{l}\text { Transitional range } \\
(10 \mathrm{~m}-100 \mathrm{~m})\end{array}$ \\
\hline 165 & -4.4 & -2.2 \\
168 & -3.8 & -3.4 \\
175 & -2.8 & -2.9 \\
221 & -2.8 & -3.6 \\
227 & -1.4 & -3.6 \\
235 & -2.4 & -3.5 \\
301 & -3.3 & -3.0 \\
312 & -3.7 & -2.3 \\
320 & -3.7 & -3.3 \\
\hline
\end{tabular}

wave numbers corresponding to scale-size range of $10 \mathrm{~m}$ to $2 \mathrm{~km}$. Spectral indices of vertical electric field fluctuations, in the intermediate and transitional scale size ranges, at altitudes shown in Fig. 6, are given in Table 1. The spectral index of intermediate scale vertical electric field fluctuations can be represented by $-2.1 \pm 0.7$ in $210-257 \mathrm{~km}$ region and by $-3.5 \pm 0.2$ in $290-330 \mathrm{~km}$ region. The spectra of the transitional scales are characterized by spectral indices of $-3.5 \pm 0.1$ in $210-290 \mathrm{~km}$ region and by $-2.8 \pm 0.5$ in $290-330 \mathrm{~km}$ region. Spectra of intermediate scales in 210-255 km region (middle panel of Fig. 6) look slightly flatter than the other two altitudes regions.

\section{Discussion}

Electric field fluctuations reported here yield scale sizes in the rocket frame of reference. As no measurements of phase velocity of plasma waves, their direction of propagation with respect to the rocket velocity vector and periods were made in the present experiment, these can not be accurately transformed in to the values in the Earth frame of reference. Qualitative estimates of values in the Earth frame of reference can, however, be made using model values of the three wave parameters.

\subsection{Vertical electric field $\left(\delta E_{V}^{\prime}\right)$}

The vertical electric field exhibits the first major peak at $135 \mathrm{~km}$. This peak is co-located with a very sharp layer of electron density wherein the electron density increased by a factor of 30 in a vertical extent of $5 \mathrm{~km}$ (Raizada and Sinha, 1999). The first major region of high electric fields (165-190 km ) coincides with similar features in the electron density in the same region, which is also termed as the valley region. This is the region where the vertical electric field exhibits largest vertical scales $(1 \mathrm{~km}-5 \mathrm{~km})$. The increase in electric field in this region (by a factor of 5 in about $2 \mathrm{~km}$ ) is slightly faster than the corresponding change in the electron density (by a factor of 5 in about $3 \mathrm{~km}$ ). Highest electric field fluctuations are observed in the region
160-190 km. Observations of irregularities in the valley region are very few. At such low altitudes, the growth rate of the Rayleigh Taylor instability would be very small because of very high ion-neutral collision frequencies. In the absence of any other plausible mechanism of generation of irregularities at these altitudes, the observed irregularities do not seem to be generated locally.

Vickrey et al. (1984) observed spectral peaks at $0.7 \mathrm{~km}$ and $1.4 \mathrm{~km}$ in the electron density and attempted to explain them in terms of an image striation theory. This theory interprets the observed irregularities as the images of irregularities in the bottom side of the F-layer produced by the Generalized Rayleigh Taylor Instability (GRTI). The theory suggests that at kilometer scales, a scale size dependent effective diffusion dominates over the classical cross-field diffusion. Some of these fluctuations reported here and earlier (between $165 \mathrm{~km}-$ $172 \mathrm{~km}$; Sinha et al., 1999), which exhibit a peak around kilometer scales, can be explained by the image striation theory of Vickrey et al. (1984). As reported earlier by Sinha et al. (1999) similar peaks are seen in the electron density fluctuations also. These electric field measurements are, therefore, the first observations of electric field, which demonstrate the validity of the image striation theory of Vickrey et al. (1984).

Electric field fluctuations around the $175 \mathrm{~km}$ region do not exhibit any peak at kilometer scales and hence some new mechanism has to be explored for their explanation.

The intermediate range irregularities $(100 \mathrm{~m}-2 \mathrm{~km})$ observed in the other two regions $(210 \mathrm{~km}-257 \mathrm{~km}$ and $290 \mathrm{~km}-330 \mathrm{~km})$ are found to co-exist with the irregularities in the electron density. The computation of the effective linear growth rate of the GRTI, made by Raizada and Sinha (1999), along with a number of other factors had shown that the observed electron density irregularities were produced by the gradient drift instability (GDI). Hence the electric field fluctuations reported here must also be generated through the gradient drift instability.

The transitional range irregularities $(10 \mathrm{~m}-100 \mathrm{~m})$ were also observed in plenty in these two regions. As seen from the power spectra, the strength of transitional scale irregularities in the electric field in $210-257 \mathrm{~km}$ and $290 \mathrm{~km}-330 \mathrm{~km}$ regions is nearly similar. The spectra of transitional scales are characterized by spectral indices of $-3 \pm 0.9$ and $-2.5 \pm 1.4$ in $210-257 \mathrm{~km}$ and $290 \mathrm{~km}-330 \mathrm{~km}$ regions, respectively. These irregularities are also produced by the gradient drift instability mechanism.

\subsection{Horizontal electric field ( $\left.\delta E_{H}^{\prime}\right)$}

It is known that the zonal electric field, which gives rise to the vertical electrodynamic drift, $V_{z}$, is given by the expression

$V_{z}=\left(E_{H} \times B\right) / B^{2}$ 
where $E_{H}$ is the zonal electric field, and $B$ is the Earth's magnetic field. As the spin axis of the rocket is inclined by about $8.8^{\circ}$ with respect to vertical and the dip angle at SHAR is $14^{\circ} \mathrm{N}$, the vertical electrodynamic drift is given by

$V_{z}=E_{H} \cos \left(8.8^{\circ}\right) / B \cos \left(14^{\circ}\right)$

Here $E_{H}$ is the horizontal electric field, i.e., the electric field measured across the rocket spin axis. The vertical electrodynamic drift was computed using the observed $E_{H}$ and expression (7). $V_{z}$ values of $100 \mathrm{~ms}^{-1}$ and $250 \mathrm{~ms}^{-1}$ were observed at $185 \mathrm{~km}$ and $292 \mathrm{~km}$ altitudes, respectively. In 165 to $175 \mathrm{~km}$ region, $V_{z}$ values as high as $50 \mathrm{~m} / \mathrm{s}$ were observed whereas, in $210-260 \mathrm{~km}$ region, $V_{z}$ ranged between 2 and $20 \mathrm{~ms}^{-1}$. The maximum velocity observed in $260-280 \mathrm{~km}$ region, was around $7 \mathrm{~ms}^{-1}$. The base of the $\mathrm{F}$ layer located around $255 \mathrm{~km}$ was seen to drift downward with $V_{z} \approx 19 \mathrm{~m} / \mathrm{s}$. This downward drift velocity of $19 \mathrm{~ms}^{-1}$ of the base of the F layer matches extremely well with the downward velocity obtained from the rate of change of $h^{\prime} F$ inferred from ionograms taken at SHAR at the time of flight (Chandra et al., 1997). This indicated the reliability of the present in situ electric field measurements.

The correlation analysis of $\delta n_{e}, \delta E_{V}^{\prime}$ and $\delta E_{H}^{\prime}$, suggests: (a) that there is a very strong correlation between $\delta n_{e}$ and $\delta E_{V}^{\prime}$, (b) there is very poor or no correlation between $\delta n_{e}$ and $\delta E_{H}^{\prime}$ and (c) that the correlation coefficient between $\delta n_{e}$ and $\delta E_{V}^{\prime}$ is a very sensitive function of the amplitude of electron density fluctuations. $\delta n_{e}$ and $\delta E_{V}^{\prime}$ are highly correlated (anticorrelated) at large (small) electron density amplitudes. These observations are at slight variance with the observations of Hysell et al. (1994), who found a strong anti-correlation between $\delta n_{e}$ and $\delta E_{H}^{\prime}$ and a very weak or no correlation between $\delta n_{e}$ and $\delta E_{V}^{\prime}$. Hysell et al. (1994) explained their observations of anti-correlation between $\delta n_{e}$ and $\delta E_{H}^{\prime}$ in terms of an eastward neutral wind (in the frame of reference of plasma) which produces a current in the vertically upward direction, which results in the generation of vertical polarization electric fields. The strong anti-correlation, between $\delta n_{e}$ and $\delta E_{V}^{\prime}$, seen in $170-180 \mathrm{~km}$ and $290-330 \mathrm{~km}$ regions, in the present data would therefore, suggest the existence of a vertically upward current in these two altitude regions, as suggested by Hysell et al. (1994). In the intermediate region of 210-257 km, the strong positive correlation between $\delta n_{e}$ and $\delta E_{H}^{\prime}$ would, by the similar arguments, imply the presence of vertically downward current. Thus the present correlation analysis suggests the existence of a sheared flow of vertical current in $160-330 \mathrm{~km}$ region.

Acknowledgements. The authors thank Professors S. Prakash, H. Chandra and Mr. R. N. Misra for their help in conducting the rocket flight. Authors are grateful to the staff of Vikram Sarabhai Space Center (VSSC), Trivandrum and Shriharikota rocket range (SHAR) for providing all the necessary facilities for this rocket flight. This work was supported by the Physical Research Laboratory, Ahmedabad.

Topical Editor M. Lester thanks P. N. Guzdar and another referee for their help in evaluating this paper.

\section{References}

Aggson, T. L., W. J. Burke, N. C. Maynard, W. B. Hanson, W. R. Hogey, and J. L. Saba, Electric field observations of equatorial bubbles, J. Geophys. Res., 97, 2997, 1992.

Aggson, T. L., H. Laakso, N. C. Maynard, and R. F. Pfaff, In-situ observations of bifurcation of equatorial ionospheric plasma depletions. J. Geophys. Res., 101, 5125-5132, 1995.

Anderson, D. N., Modeling ambient low latitude $F$ region ionosphere - A review, J. Atmos. Terr. Phys., 43, 753, 1981.

Balan, N., R. Balachandran Nair, G. Gopkumar, and P. B. Rao, Spectra of the AC electric fields in the $\mathrm{F}$ region at the magnetic equator, Adv. Space Res., 13(1), 299-302, 1993.

Balsley B. B., Electric fields in the equatorial ionosphere: A review of techniques and measurements, J. Atmos. Terr. Phys., 35, 1035, 1975.

Chandra H., R. K. Misra, M. R. Deshpande, and R. G. Rastogi, Ionospheric irregularities and their drifts at Thumba during 1964-68, Ind. J. Pure App. Phys., 8, 548, 1970.

Chandra, H., G. D. Vyas, H. S. S. Sinha, S. Prakash, and R. N. Misra, Equatorial spread F campaign over SHAR, J. Atmos. Sol. Terr. Phys., 59, 191, 1997.

Earle, G. D. and M. C. Kelley, Spectral studies of the sources of ionospheric electric fields, J. Geophys. Res., 92, 213-224, 1987.

Fahleson, U. V., Theory of electric field measurements conducted in the magnetosphere with electric probes, Space Sci. Rev., 7, 238$262,1967$.

Fahleson, U. V., M. C. Kelley, and F. S. Mozer, Investigation of the operation of a d.c. electric field detector, Planet. Space Sci., 18, 1551-1561, 1970.

Fejer, B. G., and M. C. Kelley, Ionospheric Irregularities, Rev. Geophys. Space Phys., 81, 401-454, 1980.

Fejer, B. G., D. T. Farley, R. F. Woodman, and C. Calderon, Dependence of equatorial $\mathrm{F}$ region vertical drifts on season and solar cycle, J. Geophys. Res., 84, 5792-5796, 1979.

Fejer B. G., E. R. de Paula, S. A. Gonzales, and R. F. Woodman, Average vertical and zonal $\mathrm{F}$ region plasma drifts over Jicamarca, J. Geophys. Res., 96, 13 901, 1991.

Fredricks, R. W., and F. W. Coroniti, Ambiguities in the deduction of rest frame fluctuation spectra computed in moving frames, J. Geophys. Res., 81, 5591-5595, 1976.

Forbes, J. M., and R. S. Lindzen, Atmospheric solar tides and their electrodynamic effects - III. The polarization electric field, J. Atmos. Terr. Phys., 39, 1369-1377, 1977.

Hysell, D. L., M. C. Kelley, W. E. Swartz, R. F Pfaff, and C. M. Swenson, Steepened structures in equatorial spread F 1. New observations, J. Geophys. Res., 95, 17 253-17 260, 1994.

Jahn, J. M., J. LaBelle, and R. F. Pfaff, DC electric field measurements with Guara spread-F rocket, Geophys. Res. Lett., 24, 1695-1698, 1997.

Kelley, M. C. and F. S. Mozer, A satellite survey of vector electric fields in the ionosphere at frequencies of 10 to $500 \mathrm{~Hz}$, J. Geophys. Res., 77, 4183, 1972.

Kelley, M. C., R. Pfaff, K. D. Baker, J. C. Ulwick, R. C. Livingston, C. L. Rino, and R. T. Tsunoda, Simultaneous rocket probe and radar measurements of equatorial spread F: transitional and short wavelength results, J. Geophys. Res., 87, 1575-1588, 1982.

Kudeki, E., S. Bhattacharyya, and R. F. Woodman, A new approach in incoherent scatter $\mathrm{F}$ region $\mathrm{E} \times \mathrm{B}$ drift measurements at Jicamarca, J. Geophys. Res., 104, 28 145-28 162, 1999.

Kudeki, E., B. G. Fejer, D. T. Farley, and H. M. Lerkic, Interferometer studies of equatorial $\mathrm{F}$ region irregularities and drifts, Geophys. Res. Lett., 8, 377, 1981.

Kudeki, E., C. D. Fawcett, W. L. Ecklund, P. E. Johnston, and S. J. Franke, Equatorial $150-\mathrm{km}$ irregularities observed at Pohnpei, Geophys. Res. Lett., 25, 4079-4082, 1998.

Laakso, H., T. L. Aggson, and R. F. Pfaff, Downdrafting plasma flow in equatorial bubbles., J. Geophys. Res., 99, 11 507-11 515, 1994. 
Laakso, H., N.C. Maynard, R. F. Pfaff, T. L. Aggson, W. L. Coley, P., Janhunen, and F. A. Herrero, Electric field diagnostics of the dynamics of equatorial density depletions, J. Atmos. Terr. Phys., 59(13), 1625-1631, 1997.

LaBelle, J., M. C. Kelley, and C. E. Seyler, An analysis of the role of drift waves in equatorial spread F, J. Geophys. Res., 91, 5513-5525, 1986.

LaBelle, J., J.-M. Jahn, R. F. Pfaff, W. E. Swartz, J. H. A. Sobral, M. A. Abdu, P. Muralikrishna, and E. R. dePaula, The Brazil/ Guara equatorial spread F campaign: Results of large scale measurements, Geophys. Res. Lett., 24(3), 1691-1694, 1997.

Maynard N.C., T. L. Aggson, F. A. Herrero, M. C. Liebrecht, and J. L. Saba, Average equatorial zonal and vertical ion drifts determined from San Macro D electric field measurements J. Geophys. Res., 100, 17 499-17 514, 1995.

Moffett, R. J., The equatorial anomaly in the electron distribution of the terrestrial F region, Fund. Cosmic Phys., 4, 313, 1979.

Pal S., S. Prakash, Y. B. Acharya, and R. N. Misra, A payload for the study of electric field and electron density in the equatorial region, Adv. Space Res., 2, 57-59, 1983.

Prakash, S., and S. Pal, Electric field and electron density irregularities in the equatorial electrojet, $A d v$. Space Res., 5, 205-208, 1985.

Prakash S., B. H. Subbaraya, and S. P. Gupta, Rocket measurements of ionization irregularities in the equatorial ionosphere at Thumba and identification of plasma instabilities, Ind. J. Rad. Space Phys., 1, 72-80, 1972.

Prakash, S., S. Pal, and R. Pandey, Electric field and electron density measurements in the equatorial E-region, Adv. Space Res., 2, 93-96, 1983.

Pfaff, R. F., M. C. Kelley, B. G. Fejer, N. C. Maynard, and K. D. Baker, In-situ measurements of wave electric fields in the equatorial electrojet, Geophys. Res. Lett., 9, 688, 1982.

Pfaff, R. F., M. C. Kelley, E. Kudeki, B. G. Fejer, and K. D. Baker, Electric field and plasma density measurements in the strongly driven daytime equatorial electrojet 1 . The unstable layer and gradient drift waves, J. Geophys. Res., 92, 13 578, 1988a.

Pfaff, R. F., M. C. Kelley, E. Kudeki, B. G. Fejer, and K. D. Baker, Electric field and plasma density measurements in the strongly driven daytime equatorial electrojet 2. Two stream waves, J. Geophys. Res., 92, 13 597, 1988b.

Raghavarao R., J. N. Desai, B. G. Anandarao, R. Narayanan, R. Sekar, Ranjan Gupta, V. V. Babu, and V. Sudhakar, Evidence for the large scale electric field gradient at the onset of equatorial spread F, J. Atmos. Terr. Phys., 46, 355-362, 1984.

Raghavarao R., S. P. Gupta, R. Sekar, R. Narayanan, J. N. Desai, R. Sridharan, V. V. Babu, and V. Sudhakar, In situ measurements of wind, electric fields and electron densities at the onset of equatorial spread F, J. Atmos. Terr. Phys., 49, 485-492, 1987.

Raizada, S. and H. S. S. Sinha, Some new features of electron density irregularities over SHAR during strong spread F, Ann. Geophysicae, 18(2), 141-151, 2000.

Rastogi, R. G., H. Chandra, and R. K. Misra, Features of the ionospheric drift over the magnetic equator, Space Res. XII, 983-992, 1972.

Rees, D., P. D. Bhavsar, J. N. Desai, S. P. Gupta, A. D. Farmer, and $\mathbf{P}$. Rounce, Preliminary report on the commonwealth collaborative rocket programme from Thumba equatorial rocket launching station for investigation of atmospheric and ionospheric processes, Space Res., 16, 407-412, 1976.

Richmond, A. D., Equatorial electrojet-I development of a model including winds and instabilities, J. Atmos. Terr. Phys., 35, 1083-1103, 1973.

Sastri, J. H., Equatorial anomaly in $\mathrm{F}$ region - A review, Ind. $J$. Rad. Space Phys., 19, 225, 1990

Sinha, H. S. S., S. Raizada, and R. N. Misra, First simultaneous in situ measurement of electron density and electric field fluctuations during spread $\mathrm{F}$ in the Indian zone, Geophys. Res. Lett., 20, 1669-1672, 1999.

Temerin, M., Doppler shift effects on double probe measured electric field power spectra, J. Geophys. Res., 84, 5929-5934, 1979.

Vickrey, J. F., M. C. Kelley, R. Pfaff, and S. R. Goldman, Lowaltitude image striations associated with bottomside equatorial spread F: Observations and theory, J. Geophys. Res., 89, 2955, 1984.

Vishwanathan, K. S., R. Balachandran Nair, and P. B. Rao, Simultaneous observations of $\mathrm{E}$ and $\mathrm{F}$ region electric field fluctuations at the magnetic equator, J. Atmos. Terr. Phys., 55, 185-192, 1993.

Woodman, R. F., Vertical drift velocities and east-west electric fields at the magnetic equator, J. Geophys. Res., 75, 6249-6259, 1970.

Woodman, R. F., R. G. Rastogi, and C. Calderon, Solar cycle effects on the electric fields in the equatorial ionosphere, J. Geophys. Res., 82, 5257, 1977. 